Submitted to VSI of Theoretical and Applied Fracture Mechanics, entitled Crack Paths 2018 November 2018

\title{
LIGHTWEIGHT CONSTRUCTION MATERIALS: MORTAR REINFORCED WITH DATE-PALM MESH FIBRES
}

Sabrina Vantadori, Andrea Carpinteri, Andrea Zanichelli

\begin{abstract}
Department of Engineering \& Architecture, University of Parma, Parco Area delle Scienze 181/A, 43124 Parma, Italy
\end{abstract}

\section{Corresponding Author:}

Sabrina Vantadori, email: sabrina.vantadori@unipr.it

\begin{abstract}
Nowadays, research on sustainable buildings is devoted to materials which offer advantages in terms of recyclability, low cost, environmentally-friendly features, no toxicity, biodegradability and good mechanical performance. The lightweight construction materials composed by a cement-based matrix reinforced with vegetal fibres are able to satisfy the above statements. In the present paper, the physical, mechanical and fracture properties of a cement-based mortar reinforced with datepalm mesh (DPM) fibres is experimentally analysed. The results obtained show that the positive effect of such fibres on the
\end{abstract}


ductility/weight mortar performance increases by increasing the fibre content.

KEYWORDS: date-palm mesh fibres, ductility, mortar, sustainable buildings

\section{NOMENCLATURE}

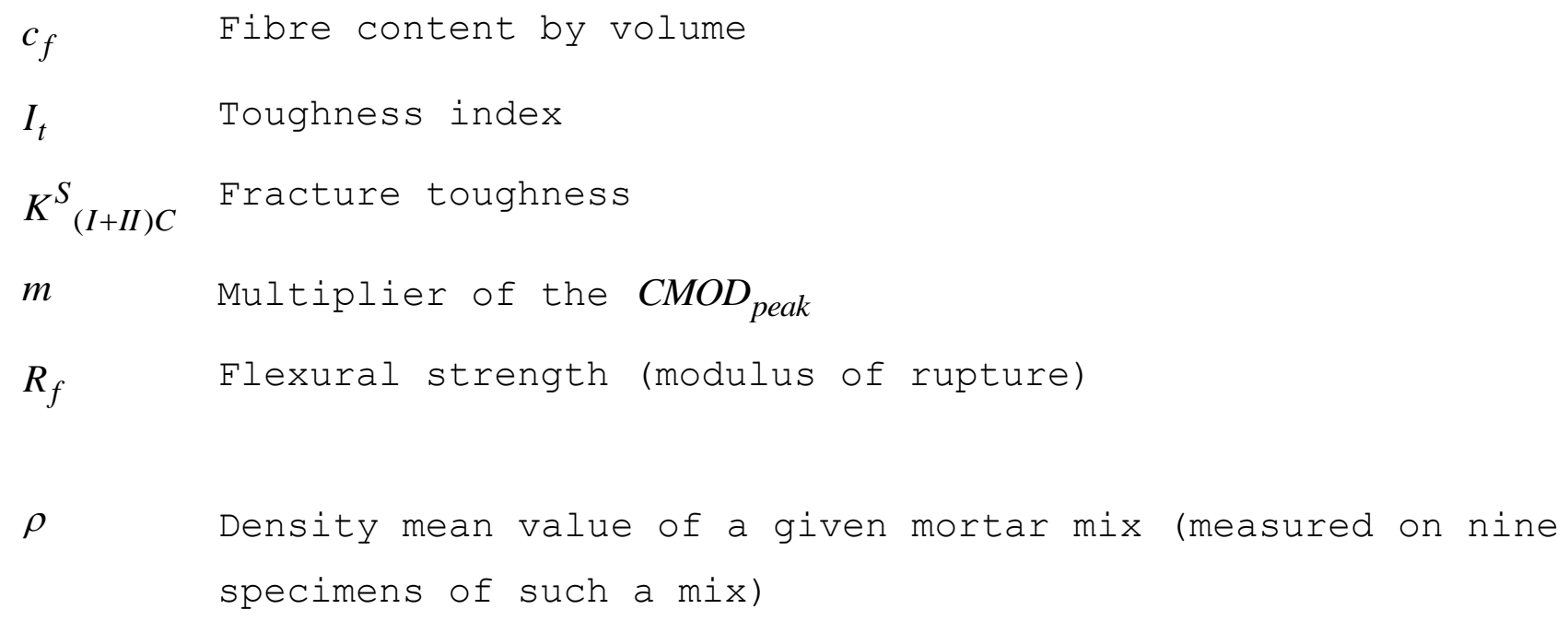

\section{ACRONYMS}

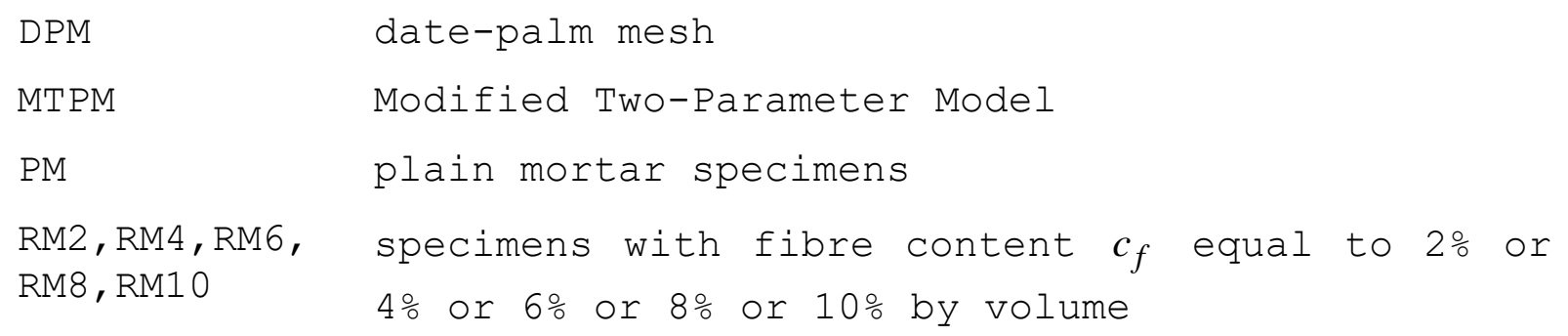




\section{INTRODUCTION}

The modern technology aiming to improve the performances of cementitious composites (concrete and mortar) has experienced fast developments during last two decades, by attracting remarkable attention worldwide.

First of all, research in such a field has been addressed to improve the compressive strength of such composites. Nowadays, concrete and mortar with strength up to 100 to $120 \mathrm{MPa}$ can readily be designed and manufactured. The drawback is that the higher the strength, the higher the brittleness. Therefore, research has been addressed to reinforce concrete and mortar by adding fibres into cement-based matrix, in order to improve their tensile strength and, consequently, their ductility (or toughness).

There are many types of fibres that can be used as reinforcement. Those of industrialised type are made in steel, polypropylene, or glass. Their effectiveness related to the tensile performance, in terms of tensile and flexural strength, fracture toughness, crack delaying, and crack size decrease, has successfully been proven [1-15]. On the other hand, the use of natural fibres (vegetable and animal), even coming from waste, is attracting attention of food industry and agriculture, and also that of the research community [16-42].

By focusing our attention on the vegetable fibres, precursor studies in such a field were those by savastano et al. $[16,17,20,22]$ who experimentally determined flexural strength 
(modulus of rupture), elastic modulus, and toughness of cementbased matrix, alternatively reinforced with eucalyptus, banana, or sisal pulps fibres. They found that, by adding 8\% of fibres to the mix, such properties (flexural strength, elastic modulus and toughness) increased with respect to the values for plain matrix.

Ramakrishna et al. [21] experimentally investigated the resistance to impact loading of cement mortar, alternatively reinforced with coir, jute, or hibiscus cannabinus fibres. They found that such a resistance was 3 to 10 times that of plain mortar.

Ali et al. [24] performed experimentally tests on coconut fibre reinforced concrete to determine flexural strength, elastic modulus, compressive strength, compressive toughness, splitting tensile strength, total toughness, and density. They found that the above static mechanical properties could increase or decrease depending on both fibre length and fibre content. The Authors also investigated damping ratio, fundamental frequency, and dynamic modulus of elasticity. From these experimental tests, it was observed an increase of damping ratio and a decrease of fundamental frequency and dynamic modulus by increasing the fibre content.

Pereira et al. [33] experimentally evaluated compressive strength, fracture resistance (in terms of J-integral value), and resistance to impact loading of cement mortar reinforced with sisal fibres. They found that the use of sisal fibres decreased 
the compressive strength, while it considerably increased both the fracture resistance and the impact energy level. Further, longer fibres showed to be more efficient than the shorter ones in promoting fracture resistance. Fantilli et al. [38] performed experimental investigations on mortar reinforced with both treated and non-treated wood fibres, by determining flexural strength, elastic modulus, and fracture toughness. They found that the mechanical properties remarkably increased by using 1\% of wool fibres by volume, with an increase of fracture toughness (with respect to plain mortar) equal to $300 \%$ when treated fibres are included in the mix.

By focusing our attention on recent studies carried out by using date-palm fibres as a mortar reinforcement (that is, the fibres used in the present paper), Ozerkan et al. experimentally evaluated both durability and strengths (tensile, compressive and flexural strength, respectively) of cement-based mortar reinforced with treated date-palm fibres. They found that tensile, compressive and flexural strengths decreased when the fibre content exceeded $0.5 \%$, whereas the durability performance analysis suggested that inclusion of fibres up to $2 \%$ improved the mortar resistance to sulfate attack. Boumhaout et al. [36] performed an experimental campaign on mortar reinforced with datepalm mesh (DPM) fibres. They found that density decreased up to 39\%, and compressive strength decreased to acceptable values also for high DPM fibre content, while the ductility was enhanced. 
The main toughening mechanisms that can take place in a cementbased composite reinforced with vegetable fibres are as follows [43,44]: fibre-matrix interface debonding with either fibre pullout or fibre fracture or crack bridging; crack deflection; microcracking.

To the best knowledge of the present authors, no studies related to the fracture behaviour of cement-based mortar reinforced with DPM fibres are available in the literature. Therefore, the present work aims to highlight both the benefic effect of such fibres in terms of toughness and the potential drawbacks (flexural strength and fracture toughness reduction). An initial research work on such a topic has been published in Ref.[42]. In Section 2, geometrical, physical and mechanical properties of both DPM fibres and mortar are discussed. Then the influence of such fibres on physical and mechanical properties (Section 3) and fracture behaviour (Section 4) of mortar is examined. A comparison with some data available in the literature is performed in section 5, and conclusions are summarised in Section 6 .

\section{MATERIALS}

\subsection{Geometrical, physical and mechanical properties of DPM fibres}

The fibres used in the present study, obtained from the date-palm named Phoenix Dactylifera, have been provided by the Laboratory of 
Civil Engineering of the University Mohamed Kheider in Algeria. The fibres are coming from the part of date-palm surrounding the trunk, named mesh, that consists of a woven mat of crossed fibres with different diameters. Details on the technique to extract fibres from the mesh can be found in Ref.[45]. After this process, the fibres have a length between 200 and $500 \mathrm{~mm}$ (Figure 1) .

\section{Figure 1.}

The geometrical sizes and physical properties, listed in Table 1, are taken from the literature [45], since the fibres used in the present research work come from the same geographic area as those employed by Taallah et al.[45]. It can be observed that the variability in diameter is significant (equal to 50.4\%), which is typical of natural fibres. The mechanical properties listed in Table 2 are also taken from Ref.[45].

Table 1 .

Table 2 .

According to the definition given by Banthia et al. [46], fibres with a length greater than $25 \mathrm{~mm}$ and diameter between 0.3 and $3 \mathrm{~mm}$ are considered macro-fibres, while fibres with a length less than $20 \mathrm{~mm}$ and diameter less than $20 \mu \mathrm{m}$ are considered microfibres. In the present paper, fibres are cutted into pieces of length between 7 and $10 \mathrm{~mm}$ and, therefore, they do not completely 
satisfy the above definitions. In such a sense, they can be classified as hybrid natural fibres.

\subsection{Cement-based mortar composition}

The experimental tests presented hereafter have been performed on specimens with the following mix proportion per $\mathrm{m}^{3}$ of mortar, according to UNI EN 196-1 [47]: 580kg of cement, $320 \mathrm{~kg}$ of water, $1750 \mathrm{~kg}$ of sand, and $6 \mathrm{~kg}$ of superplasticizer.

The cement is a limestone Portland cement, type 42.5 CEM II/ALL, according to UNI EN 197-1 [48]. The sand is of silica type, with a grain size distribution according to UNI EN 196-1 [47] . The superplasticizer is based on natural and synthetic polymers, according to UNI EN 934-2 - Tables T11.1 and T11.2 [49].

This mortar mix is modified by incorporating DPM fibres as a reinforcement, in a dosage as follows: $0 \mathrm{~kg} / \mathrm{m}^{3}$ (PM, plain mortar), $28 \mathrm{~kg} / \mathrm{m}^{3}$ (RM2, fibre content $c_{f}$ equal to $2 \%$ by volume), $56 \mathrm{~kg} / \mathrm{m}^{3}$ $\left(\mathrm{RM} 4, c_{f}=4 \%\right), 84 \mathrm{~kg} / \mathrm{m}^{3} \quad\left(\mathrm{RM} 6, c_{f}=6 \%\right), 112 \mathrm{~kg} / \mathrm{m}^{3} \quad\left(\mathrm{RM} 8, c_{f}=8 \%\right)$, and $140 \mathrm{~kg} / \mathrm{m}^{3}\left(\mathrm{RM} 10, c_{f}=10 \%\right)$. Blending is done by hand.

Before their inclusion in the matrix, fibres are submerged in water for $24 \mathrm{~h}$ at room temperature between $20^{\circ}$ and $24^{\circ} \mathrm{C}$ and then dried in air. Such a procedure is needed in order to avoid that fibres absorb too many water of mix during casting.

Note that, for each casting, superplasticizer adjustment is performed through a workability test according to UNI EN 1015-3 
[50] (Figure 2). More precisely, the content of the additive is adjusted in order to produce a flow of about $110 \%$ by jolting the flow table for 15 times in 30 s.

\section{Figure 2.}

\subsection{Cement-based mortar specimen preparation}

For each of the six mortar mix types described in section 2.2 (PM, RM2, RM4, RM6, RM8, RM10), nine beam specimens are casted, whose geometrical sizes depend on the test type to be performed, as is detailed in Section 3.

After each mold is filled, vibration is carried out for $30 \mathrm{~s}$ with a conventional vibrating table in order to ensure a good compaction. The consolidation is performed at room temperature and relative umidity condition of 50\% for 24h. After demolding, curing occurs in saturated conditions and room temperature for 28 days .

\section{INFLUENCE OF DPM FIBRES ON PHYSICAL AND MECHANICAL PROPERTIES OF MORTAR}

\subsection{Mortar density}

For each specimen, density is determined after curing, according to UNI EN 1015-10 [51]. Firstly, the weight of each water saturated specimen is recorded. Then, the specimen is maintained 
at $105^{\circ} \mathrm{C}$ in oven until one weight variation is further recorded. Finally, density is computed according to the above UNI EN Recommendation (Ref.[51]), and the density mean values, $\rho$, measured on nine specimens for each of the six mortar mix types, are listed in Table 3.

\section{Table 3 .}

It can be observed that there is not a significant decrease of density by increasing the dosage of fibres up to $140 \mathrm{~kg}$ per $1 \mathrm{~m}^{3}$ of mortar. Such a decrease with respect to plain mortar ranges from 1\% (RM2 $\mathrm{mix}$ ) to 8\% (RM10 $\mathrm{mix})$, and is due to (i) increase of porosity by including fibres, and (ii) alveolar structure of fibres. The mean value of $\rho$ is $2563.23 \mathrm{~kg} / 1 \mathrm{~m}^{3}$ with a standard deviation of $69.43 \mathrm{~kg} / 1 \mathrm{~m}^{3}$, being such values influenced by the saturation time, equal to 28 day in the present study.

\subsection{Mortar flexural strength}

Three beams (sizes: $40 \mathrm{~mm} \times 40 \mathrm{~mm} \times 160 \mathrm{~mm}$ ) for each mix are subjected to three-point bending (span equal to $120 \mathrm{~mm}$ ), under load control with loading rate equal to $44 \mathrm{~N} / \mathrm{s}$. The load is measured through the load cell of the Instron 8862 testing machine shown in Figure 3 (load capacity equal to $100 \mathrm{kN}$ and accuracy equal to $\pm 0.02 \%)$

Figure 3. 
For each mortar mix, flexural strength $R_{f}$ is evaluated as the average value related to the above three beams, according to UNI EN 196-1 [47]. Such results are shown in Figure 4 together with the corresponding standard deviation error bars.

\section{Figure 4 .}

It can be observed that there is a significant decrease of flexural strength, with respect to plain mortar, when DPM fibres are incorporated. Such a behaviour is due to: (i) increase of porosity by including fibres; (ii) poor lavorability by increasing the fibre content; (iii) low elastic modulus of fibres in comparison with that of mortar.

Such a decrease with respect to plain mortar ranges from 9\% (RM2 mix) to 52\% (RM10 mix), and can be considered to be significant only for high fibre contents: from RM4 mix (decrease equal to $17 \%$ ) to $\operatorname{RM10} \operatorname{mix}$ (decrease equal to $47 \%$ ).

According to this analysis, there is not a strong evidence that DPM fibres reduce $\boldsymbol{R}_{f}$, at least up to fibre volume content lower that 4\%: the differences in $R_{f}$ values could be due to both aleatory variability of the mix composition and measurement errors. 


\section{INFLUENCE OF DPM FIBRES ON FRACTURE BEHAVIOUR OF MORTAR}

For each mortar mix, fracture toughness is computed according to the Modified Two-Parameter Model (MTPM), recently proposed by the authors $[\mathbf{1 0}, \mathbf{1 5}, \mathbf{4 2}, \mathbf{5 2}, \mathbf{5 3}]$. Six notched specimens $(15 \mathrm{~mm} \times 30 \mathrm{~mm} \times$ $160 \mathrm{~mm}$ ) with a notch length equal to $10 \mathrm{~mm}$ and a notch width lower than $3.175 \mathrm{~mm}$ are subjected to three-point bending (span equal to $120 \mathrm{~mm}$ ), under Crack Mouth Opening Displacement (CMOD) control with rate equal to $0.1 \mathrm{~mm} / \mathrm{h}$. The load is measured through the load cell of the testing machine shown in Figure 3. The clip gauge has a maximum travel equal to $4 \mathrm{~mm}$ and an accuracy equal to $\pm 0.05 \%$.

\subsection{Mortar fracture toughness}

By applying the MTPM, the fracture toughness $K_{(I+I I) C}^{S}$ is computed as the average value related to six beams for each mortar mix. Such values are shown in Figure 5 together with the corresponding standard deviation error bars.

\section{Figure 5 .}

It can be observed a significant decrease of fracture toughness, with respect to plain mortar, when DPM fibres are included in the mortar. The causes of such a behaviour are the same ones discussed in section 3.2 related to flexural strength.

Such a decrease with respect to plain mortar ranges from 7\% (RM2 mix) to 66\% (RM10 mix), and can be considered to be 
significant only for high fibre contents: from RM6 mix (decrease equal to $32 \%$ ) to $\mathrm{RM} 10 \mathrm{mix}$ (decrease equal to 58\%).

Such as for $R_{f}$ (Section 3.2), there is not a strong evidence that DPM fibres reduce $K_{(I+I I) C}^{s}$ at least up to fibre volume content lower than 6\%, and the differences in $K_{(I+I I) C}^{s}$ values could be due to both aleatory variability of the mix composition and measurement errors.

The main toughening mechanisms observed are:

(a) fibre-matrix interface debonding with fibre pull-out, and fibre-matrix interface debonding with fibre fracture (Figure $6(a)) ;$

(b) fibre-matrix interface debonding and crack bridging (Figure $6(\mathrm{~b}))$

(c) crack deflection (Figure 6(c)).

Figure 6 .

\subsection{Toughness index}

The toughness index $I_{t}$ can be defined as the ratio between the area under load-CMOD curve up to a prescribed multiplier $m$ of $C M O D_{\text {peak }}$ (which is the CMOD value at the peak load) and the area under the same curve up to $C M O D_{\text {peak }}$ (Figure 7).

Figure 7 . 
Now five different values of the multiplier $m$ are examined (1, 3, 5, 10 and 15), and the toughness index is computed as the average of the values related to six beams, for each of the six mortar mix types (PM, RM2, RM4, RM6, RM8, RM10). The results obtained are plotted in Figure 8, where the curves overlap with each other up to a CMOD value equal to about 3 times $C M O D_{\text {peak }}$ • Such a behaviour denotes that inclusion of DPM fibres starts to significantly delay the growth of macroscopic crack from CMOD $=3$ х $C M O D_{\text {peak }} \cdot$

\section{Figure 8 .}

It can be noted that, by adding fibres, a significant improvement of mortar ductility is obtained (Figure 8). As a matter of fact, the increase of $I_{t}$ with respect to that for plain mortar ranges from 27\% (RM2 mix) to $162 \%$ (RM10 mix) when $m$ is equal to 15. This analysis suggests that the DPM fibre inclusion produces an increase of the required energy for the beam collapse.

\subsection{Performance index}

The performance index related to fracture toughness for a given mortar mix is here defined as the ratio between $I_{t}$ at $m=15$ and the density $\rho$ of the mix (see Table 3). Then, the performance index value of each mortar mix type examined is normalised with respect to that of plain mortar and plotted in Figure 9. It can 
be remarked a significant improvement of ductility/weight performance by increasing the fibre content.

\section{Figure 9.}

For the examined mortar mix types reinforced with DPM fibres, the performance index is determined to increase from 29\% (RM2 mix) to $181 \%$ (RM10 mix) with respect to that of plain mortar.

\section{COMPARISON WITH LITERATURE DATA}

The data taken from the literature for comparison [36] refer to mortar reinforced with DPM fibres coming from the same geographic area as those employed in the present research work. The comparison is performed in terms of flexural strength.

The experimental tests reported in Ref.[36] have been carried out on specimens characterised by a mass ratio of $3 / 4$ of sand and 1/4 of cement. The mass ratio related to water/cement is equal to 0.6. The cement is a Portland CPJ35 cement, with a composition according to Moroccan standard NM.10.01.004 [54]. The sand is of river type, with a grain size distribution according to NM. $10.01 .700 \quad[55]$.

The mortar mix is modified by incorporating DPM fibres as a reinforcement, by considering seven values of volume ratio: 0\%, 21\%, 27\%, 31\%, 35\%, 48\%, and 51\%. Fibres are cut into pieces of length between 20 and $50 \mathrm{~mm}$. In order to allow a good 
homogenisation, a mixer is used at low speed. After demolding, curing occurs in saturated conditions at $20^{\circ} \pm 1^{\circ} \mathrm{C}$ for 28 days.

For each mortar mix, the flexural strength is evaluated according to Moroccan standard NM.10.01.005 [56]. Such a measure is performed on $40 \mathrm{~mm} \times 40 \mathrm{~mm} \times 160 \mathrm{~mm}$ beam specimens.

Figure 10 shows as the flexural strength decreases by increasing the fibre volume content [36]. Note that a decrease has been also observed by the present authors in section 3.2, where the reasons of such a trend have been highlighted. The $R_{f}$ values obtained in the present study are also plotted in this Figure.

\section{Figure 10.}

We can remark that the maximum fibre length in Ref.[36] is up to 5 times greater than the maximum one used here. Thereore, porosity in the literature case should be greater than that in the present study, and the decrease of $R_{f}$ in the first case should be faster than that in the second one. Indeed, the opposite occurs for fibre content between 2 and 10\% (see Figure 10), and this could be due to the fact that data in Ref.[36] refer to blendings prepared by means of a mixer, whereas blendings are prepared manually in the present study.

Note that the slope of the curve taken from the literature, evaluated between 21\% and 27\% of fibre content (dashed line on the 
right-hand side), agrees with that of the linear trend obtained from the present study results for fibre content between $2 \%$ and 10\% (dashed line on the left-hand side).

\section{CONCLUSIONS}

In the present paper, influence of DPM fibres on the physical, mechanical and fracture properties of a mortar have been analysed. By varying the content fibre from 2\% to 10\% by volume, the following conclusions can be drawn:

(a) By adding fibres, the decrease in mortar density is not significant;

(b) The decrease of flexural strength (with respect to that of plain mortar) is significant for fibre content greater than $4 \%$ by volume. It is equal to $47 \%$ for RM10 mix;

(c) The decrease of fracture toughness (with respect to that of plain mortar) is significant for fibre content greater than 6\% by volume. It is equal to 58\% for RM10 mix;

(d) The increase of required energy for the beam collapse (with respect to that of plain mortar) is significant. It is equal to 162\% for RM10 mix;

(e) Four toughening mechanisms have been observed: crack deflection; fibre-matrix interface debonding with either fibre pull-out or fibre fracture or crack bridging. 


\section{ACKNOWLEDGEMENTS}

The authors gratefully acknowledge the financial support provided by the Italian Ministry for University and Technological and Scientific Research (MIUR), Research Grant PRIN 2015 No. 2015JW9NJT on "Advanced mechanical modeling of new materials and structures for the solution of 2020 Horizon challenges". Moreover, the authors gratefully acknowledge Ruredil s.p.a. for the supply of the superplasticizer employed in the production of mortar specimens.

\section{REFERENCES}

[1] V.S. Gopalaratnam, S.P. Shah, Tensile failure of steel fiberreinforced mortar, J. Eng. Mech. 113 (5) (1987) 635-652.

[2] M. Grzybowski, S.P. Shah, Shrinkage cracking of fiber reinforced concrete, Mater. J. 87 (2) (1990) 138-148.

[3] A.-B. Eissa, G. Batson, Model for predicting the fracture process zone and R-curve for high strength FRC, Cem. Concr. Compos. 18 (2) (1996) 125-33.

[4] P.K. Nelson, V.C. Li, T. Kamada, Fracture toughness of microfiber reinforced cement composites, J. Mater. Civ. Eng. 14 (5) (2002) 384-91.

[5] E.K. Horszczaruk, Hydro-abrasive erosion of high performance fiber-reinforced concrete, Wear 267 (1-4) (2009) 110-115.

[6] R.S. Olivito, F.A. Zuccarello, An experimental study on the tensile strength of steel fiber reinforced concrete, Compos. Part B Eng. 41 (3) (2010) 246-255.

[7] J.P. Firmo, J.R. Correia, L.A. Bisby, Fire behaviour of FRPstrengthened reinforced concrete structural elements: A state-ofthe-art review, Compos. Part B Eng. 80 (2015) 198-216.

[8] F. Bencardino, L. Rizzuti, G. Spadea, R.N. Swamy, Experimental evaluation of fiber reinforced concrete fracture properties, Comp. Part B Eng. 41 (1) (2010) 17-24.

[9] V. Corinaldesi, A. Nardinocchi, Mechanical characterization of Engineered Cement-based Composites prepared with hybrid fibres and expansive agent, Compos. Part B Eng. 98 (2016) 389-396.

[10] S. Vantadori, A. Carpinteri, G. Fortese, C. Ronchei, D. Scorza, Mode I fracture toughness of fibre-reinforced concrete by means of a modified version of the two-parameter model, Proc. Struct. Int. 2, (2016) 2889-2895.

[11] A., Enfedaque, M.G. Alberti, J.A. Paredes, J.C. Gálvez, Interface properties of polyolefin fibres embedded in self- 
compacting concrete with a bond improver admixture, Theor. Appl. Fract. Mec. 90 (2017) 287-293.

[12] A. Carpinteri, G. Fortese, C. Ronchei, D. Scorza, S. Vantadori, Mode I fracture toughness of fibre reinforced concrete, Theor. Appl. Fract. Mech. 91 (2017) 66-75.

[13] Q. Liu, P. Qiao, Mixed mode fracture characterization of GFRP-concrete bonded interface using four-point asymmetric endnotched flexure test, Theor. Appl. Fract. Mech. 92 (2017) 155-166.

[14] S. Gali, K.V.L. Subramaniam, Multi-linear stress-crack separation relationship for steel fiber reinforced concrete: Analytical framework and experimental evaluation, Theor. Appl. Fract. Mech. 93 (2018) 33-43.

[15] S. Vantadori, A. Carpinteri, L.-P. Guo, C. Ronchei, A. Zanichelli, Synergy assessment of hybrid reinforcements in concrete, Comp. Part B: Eng. 147 (2018) 197-206.

[16] J. Savastano, P.G. Warden, R.S.P. Coutts, Ground iron blast furnace slag as a matrix for cellulose-cement materials, Cem. Concr. Compos. 23 (2001) 389-397.

[17] J. Savastano, P.G. Warden, R.S.P. Coutts, Performance of lowcost vegetable fibre-cement composites under weathering, in: $J$. Duncan (Eds), Proceedings of the CIB World Building Congress, Wellington, 2001.

[18] ACI Committee 544, State-of-the-Art Report on Fiber Reinforced Concrete, Reported by ACI Committee 544, ACI Struct. J. 96 (2002) (Reapproved).

[19] R.D. Tolêdo Romildo D., K. Ghavami, G.L. England, K. Scrivener, Development of vegetable fibre-mortar composites of improved durability, Cem. Concr. Comp. 25 (2) (2003) 185-196.

[20] J. Savastano, P.G. Warden, R.S.P. Coutts, Potential of alternative fibre cements as building materials for developing areas, Cem. Concr. Compos. 25 (6) (2003) 585-592.

[21] G. Ramakrishna, T. Sundararajan, Impact strength of a few natural fibre reinforced cement mortar slabs: a comparative study, Cem. Concr. Compos. 27 (5) (2005) 547-553.

[22] J. Savastano, P.G. Warden, R.S.P. Coutts, Microstructure and mechanical properties of waste fibre-cement composites, Cem. Concr. Compos. 27 (5) (2005) 583-92.

[23] F. Pacheco-Torgal, S. Jalali, Cementitious building materials reinforced with vegetable fibres: A review, Constr. Build. Mater. 25 (2) (2011) 575-581.

[24] M. Ali, A. Liu, H. Sou, N. Chouw, Mechanical and dynamic properties of coconut fibre reinforced concrete, Constr. Build. Mater. 30 (2012) 814-825.

[25] M. Ali, N. Chouw, Experimental investigation on coconut-fibre rope tensile strength and pullout from coconut fibre reinforced concrete, Constr. Build. Mater. 41 (2013) 681-690.

[26] I. Merta, E.K. Tschegg, Fracture energy of natural fibre reinforced concrete, Constr. Build. Mater. 40 (2013) 991-997. 
[27] N.G. Ozerkan, B. Ahsan, S. Mansour, S.R. Iyengar, Mechanical performance and durability of treated palm fiber reinforced mortars, Int. J. Sustain. Built Environ. 2 (2013) 131-142.

[28] S. Vajje, study on addition of the natural fibers into concrete, Int. J. Technol. Enhanc. Emerg. Eng. Res. 2 (11) (2013) 213-218.

[29] X. Zhou, S.H. Ghaffar, W. Dong, O. Oladiran, M. Fan, Fracture and impact properties of short discrete jute fibre-reinforced cementitious composites, Mater. Des. 49 (2013) 35-47.

[30] C. Diao, T. Dowding, S. Hemsri, R.S. Parnas, Toughened wheat gluten and treated coconut fiber composite, comp. Part A 58 (2014) 90-97.

[31] M. Ardanuy, J. Claramunt, R.D. Toledo Filho, Cellulosic fiber reinforced cement-based composites: A review of recent research, Constr. Build. Mater. 79 (2015) 115-128.

[32] P. Lertwattanaruk, A. Suntijitto, Properties of natural fiber cement materials containing coconut coir and oil palm fibers for residential building applications, Constr. Build. Mater. 94 (2015) $664-669$.

[33] M.V. Pereira, R. Fujiyama, F. Darwish, G. T. Alves, On the strengthening of Cement Mortar by Natural Fibers, Mat. Res. 18 (1) (2015) 177-183.

[34] C.L. Hwang, V.A. Tran, J.W. Hong, Y.C. Hsieh, Effects of short coconut fiber on the mechanical properties, plastic cracking behavior, and impact resistance of cementitious composites, Constr. Build. Mater. 127 (2016) 984-992.

[35] O. Onuaguluchi, N. Banthia, Plant-based natural fibre reinforced cement composites: a review, Cem. Concr. Comp. 68 (2016) 96-108.

[36] M. Boumhaout, L. Boukhattem, H. Hamdi, B. Benhamou, F. Ait Nouh, Thermomechanical characterization of a bio-composite building material: mortar reinforced with date palm fibers mesh, Constr. Build. Mat. 135 (2017) 241-250.

[37] G. Araya-Letelier, F.C. Antico, M. Carrasco, P. Rojas, C.M. García-Herrera, Effectiveness of new natural fibers on damagemechanical performance of mortar, Constr. Build. Mater. 152 (2017) $672-682$.

[38] A.P. Fantilli, S. Sicardi, F. Dotti, The use of wool as fiber-reinforcement in cement-based mortar, Constr. Build. Mater. 139 (2017) 562-569.

[39] A. Razmi, M.M. Mirsayar, on the mixed mode I/II fracture properties of jute fiber-reinforced concrete, Constr. Build. Mater. 148 (2017) 512-520.

[40] D.G. Soltan, P. das Neves, A. Olvera, H. Savastano Junior, V.C. Li, Introducing a curauá fiber reinforced cement-based composite with strain-hardening behavior, Ind. Crops. Prod. 103 (2017) 1-12.

[41] G. Araya-Letelier, J. Concha-Riedel, F.C. Antico, C. Valdés, G. Cáceres, Influence of natural fiber dosage and length on adobe 
mixes damage-mechanical behavior, Constr. Build. Mater. 174 (2018) 645-655.

[42] O. Benaimeche, A. Carpinteri, M. Mellas, C. Ronchei, D. Scorza, S. Vantadori, The influence of date palm mesh fibre reinforcement on flexural and fracture behaviour of a cement-based mortar, Comp. Part B: Eng. 152 (2018) 292-299.

[43] W.O. Soboyejo, Toughening mechanisms, in: W.O. Soboyejo (Eds.), Mechanical properties of engineered materials. Marcel Dekker Publishers, New York, 2002, pp. 414-55.

[44] S.P. Shah, S.E. Swartz, C. Ouyang, Fracture mechanics of concrete: applications of fracture mechanics to concrete, rock, and other quasi-brittle materials, John Wiley \& Sons, New York, 1995.

[45] B. Taallah, A. Guettala, S. Guettala, A. Kriker, Mechanical properties and hygroscopicity behaviour of compressed earth block filled by date palm fibers, Constr. Build. Mater. 59 (2014) 161168 .

[46] N. Banthia, M. Azzabi, M. Pigeon, Restrained shrinkage cracking in fiber reinforced cementitious composites, Mater. Struct. 26 (7) (1993) 405-413.

[47] UNI EN 196-1:2016 European Recommendation, Methods of testing cement - Part 1: Determination of strength, 2016.

[48] UNI EN 197-1:2011 European Recommendation, Cement - Part 1: Composition, specifications and conformity criteria for common cements, 2011.

[49] UNI EN 934-2:2012 European Recommendation, Admixtures for concrete, mortar and grout - Part 2: Concrete admixtures Definitions, requirements, conformity, marking and labelling, 2012 .

[50] UNI EN 1015-3:2007 European Recommendation, Methods of test for mortar for masonry, Part 3: Determination of consistence of fresh mortar (by flow table), 2007.

[51] UNI EN 1015-10:2007 European Recommendation, Methods of test for mortar for masonry - Part 10: Determination of dry bulk density of hardened mortar, 2007.

[52] S. Vantadori, A. Carpinteri, G. Fortese, C. Ronchei, D. Scorza, Mode I fracture toughness of fibre-reinforced concrete by means of a modified version of the two-parameter model, Proc. Struct. Integr. 2 (2016) 2889-2895.

[53] A. Carpinteri, F. Berto, G. Fortese, C. Ronchei, D. Scorza, S. Vantadori, Modified two-parameter fracture model for bone, Eng. Fract. Mech. 174 (2017) 44-53.

[54] NM 10.1.004, Liants hydrauliques, Ciments et les constituants des ciments, Partie I: Composition, specifications et criteres de conformite, 2018 .

[55] NM 10.1.700. Essais pour déterminer les caractéristiques géométriques des granulats - Détermination de la granularité Analyse granulométrique par tamisage, 2008.

[56] NM 10.1.005, Liants hydrauliques, Techniques des essais des ciments, 2008 . 
Submitted to VSI of Theoretical and Applied Fracture Mechanics, entitled Crack Paths 2018

November 2018

LIGHTWEIGHT CONSTRUCTION MATERIALS: MORTAR REINFORCED WITH DATE-PALM MESH FIBRES

\author{
Sabrina Vantadori, Andrea Carpinteri, Andrea Zanichelli \\ Department of Engineering \& Architecture, University of Parma, \\ Parco Area delle Scienze 181/A, 43124 Parma, Italy \\ Corresponding Author: Sabrina Vantadori, \\ sabrina.vantadorieunipr.it
}

FIGURES AND TABLES 


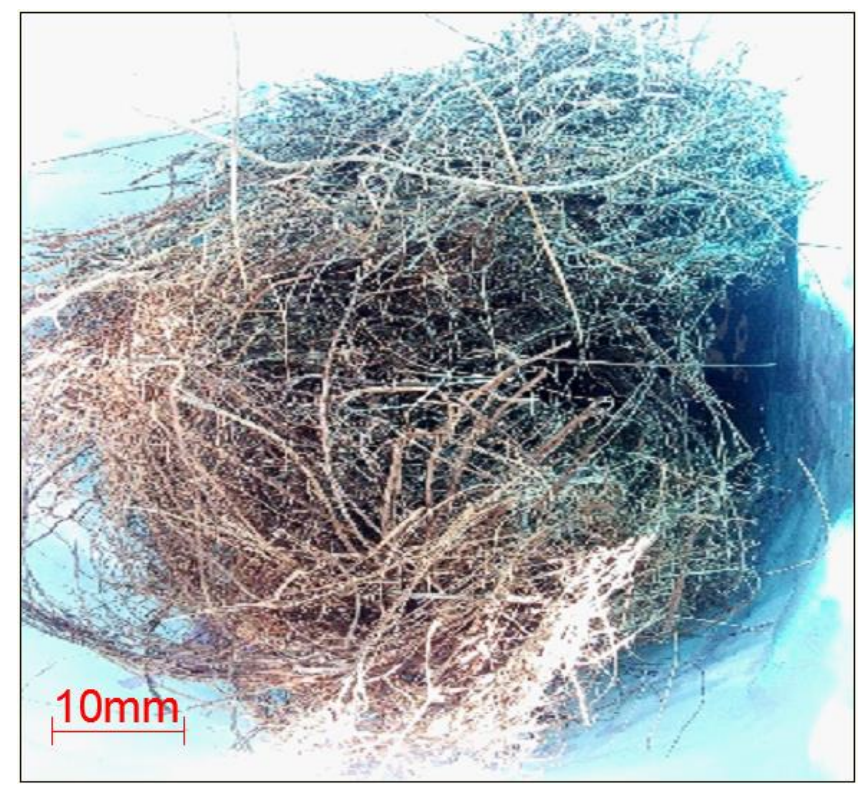

Figure 1. DPM (date-palm mesh): single fibres.

Table 1. Geometrical sizes and physical properties of DPM fibres [45].

\begin{tabular}{lll}
\hline Property & Min. & Max. \\
\hline Diameter $[\mathrm{mm}]$ & 0.1 & 0.8 \\
\hline Apparent density $\left[\mathrm{kg} / \mathrm{m}^{3}\right]$ & 512 & 1089 \\
\hline Specific density $\left[\mathrm{kg} / \mathrm{m}^{3}\right]$ & 1300 & 1450 \\
\hline Natural moisture content $[\%]$ & 9.5 & 10.5 \\
\hline Water absorption to saturation $[\%]$ & 97 & 203 \\
\hline
\end{tabular}

Table 2. Mechanical properties of DPM fibres [45].

\begin{tabular}{llll}
\hline Property & \multicolumn{3}{c}{ Lenght $[\mathrm{mm}]$} \\
\cline { 2 - 4 } & $\mathbf{1 0 0}$ & $\mathbf{6 0}$ & $\mathbf{2 0}$ \\
\hline Tensile strength [MPa] & $170 \pm 40$ & $240 \pm 30$ & $290 \pm 20$ \\
\hline Elengation [\%] & $16 \pm 3$ & $12 \pm 2$ & $11 \pm 2$ \\
\hline Elastic modulus $[\mathrm{GPa}]$ & $4.74 \pm 2$ & $5.00 \pm 2$ & $5.25 \pm 2$ \\
\hline
\end{tabular}



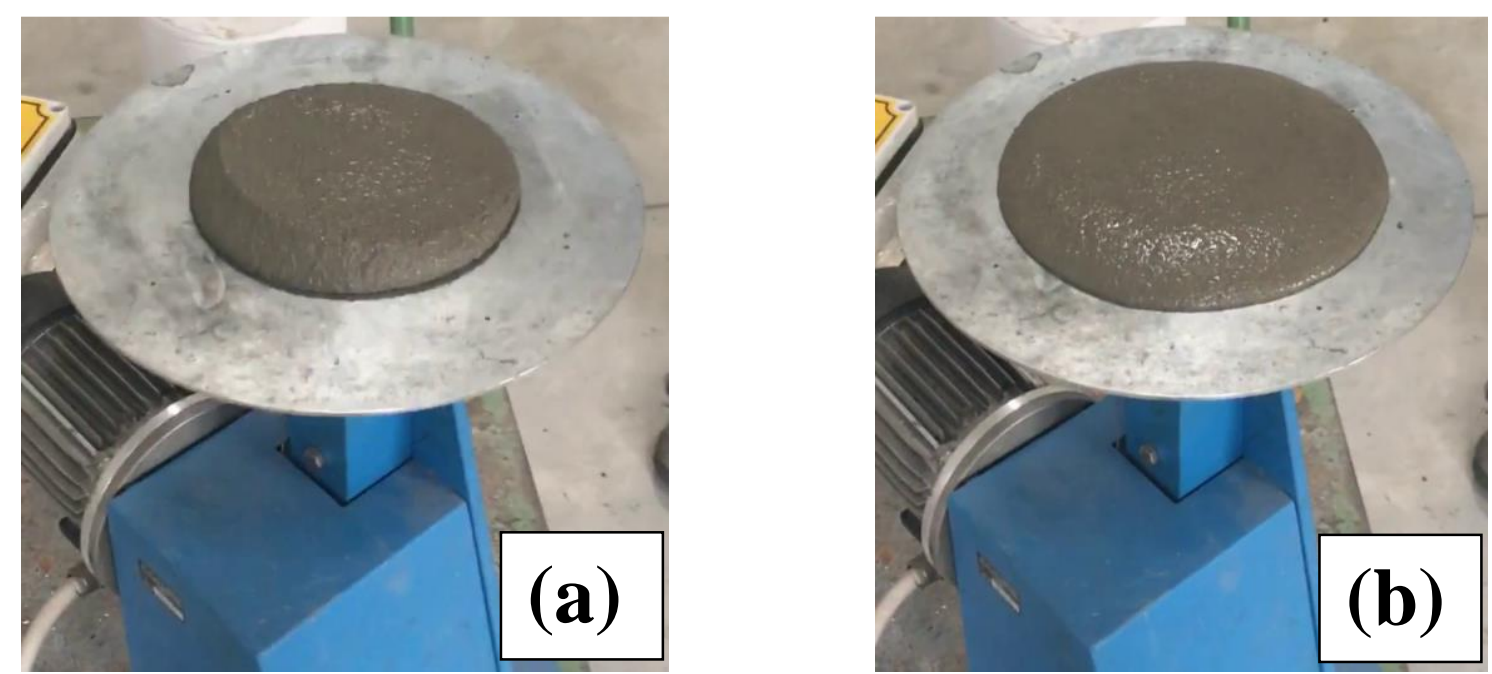

Figure 2. Workability test at: (a) 5s, and (b) $30 \mathrm{~s}$ (end of test).

Table 3. Density mean value measured on nine specimens for each mortar mix.

\begin{tabular}{ll}
\hline Mortar mix & $\begin{array}{c}\text { Density, } \rho \\
{\left[\mathrm{kg} / \mathrm{m}^{3}\right]}\end{array}$ \\
\hline PM & 2656 \\
\hline RM2 & 2618.89 \\
\hline RM4 & 2581.78 \\
\hline RM6 & 2544.67 \\
\hline RM8 & 2507.56 \\
\hline RM10 & 2470.45 \\
\hline
\end{tabular}




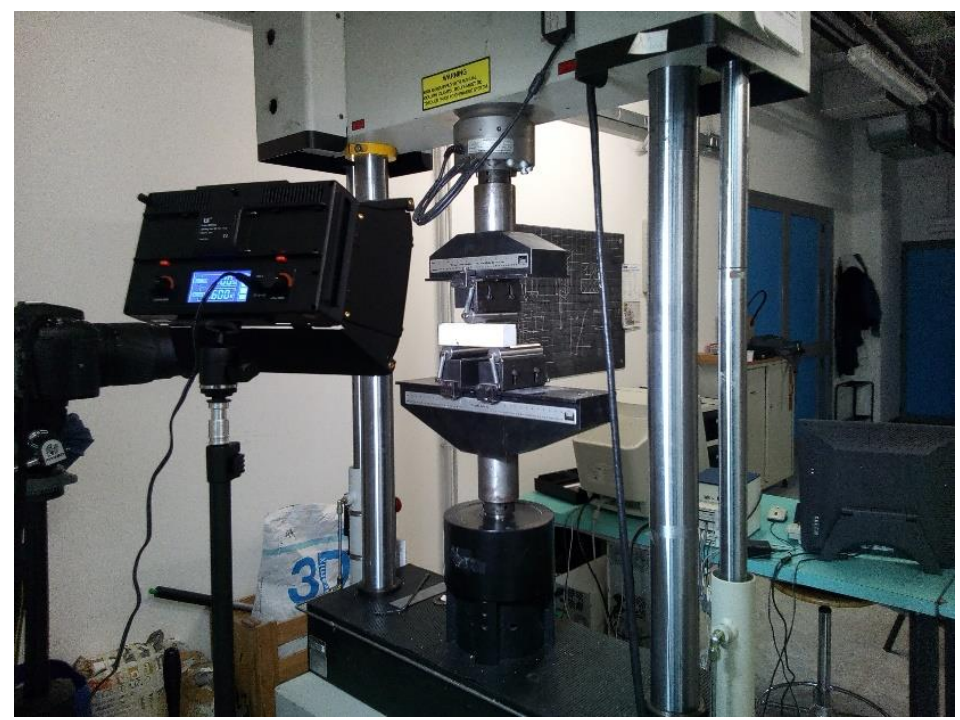

Figure 3. Testing machine and three point bending test setup. 


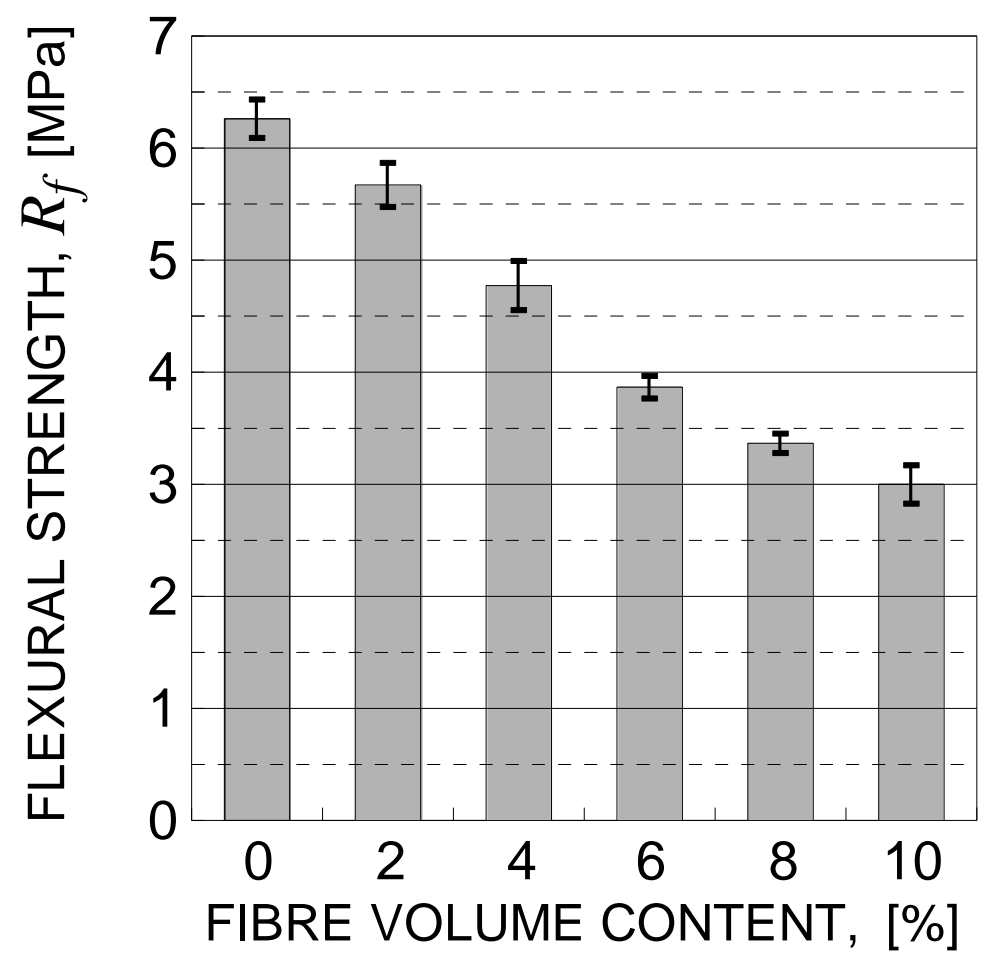

Figure 4. Flexural strength at 28 days against DPM fibre content by volume. 


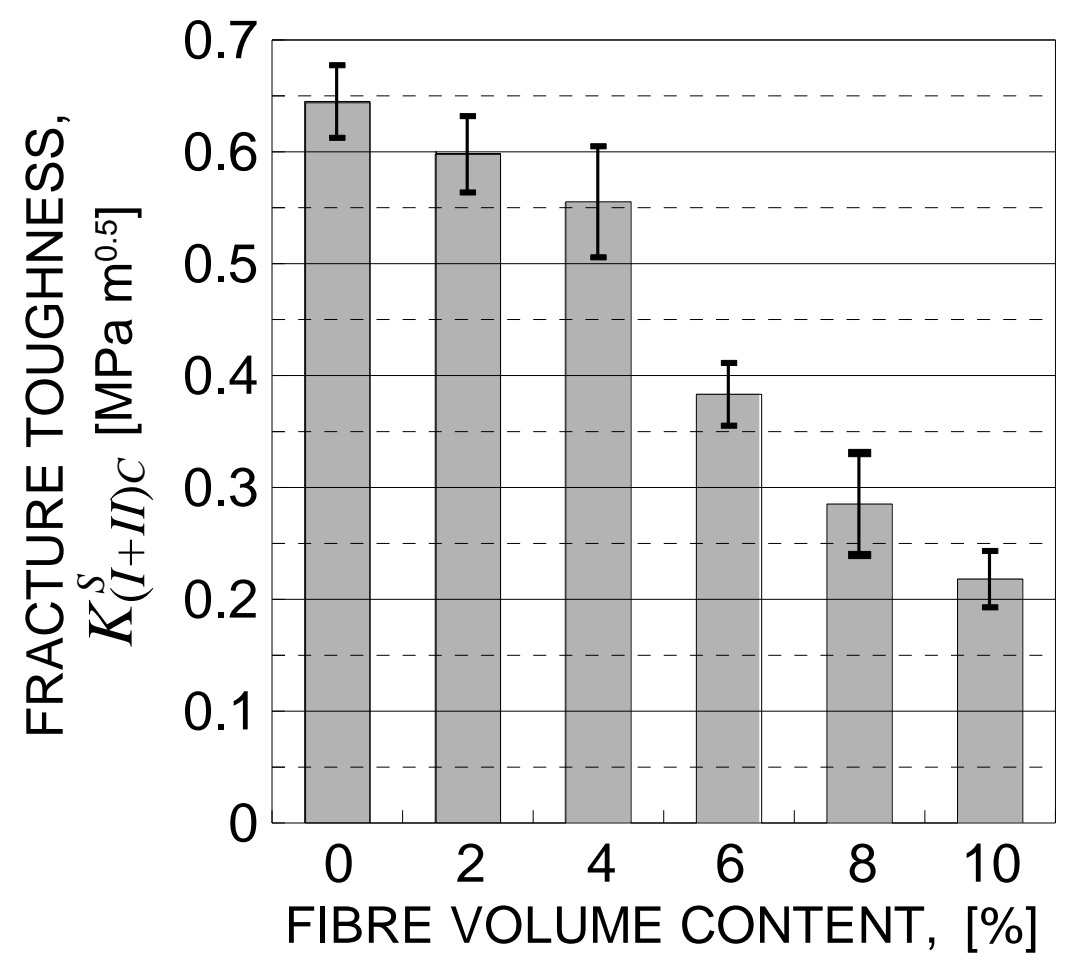

Figure 5. Fracture toughness at 28 days against DPM fibre content by volume. 

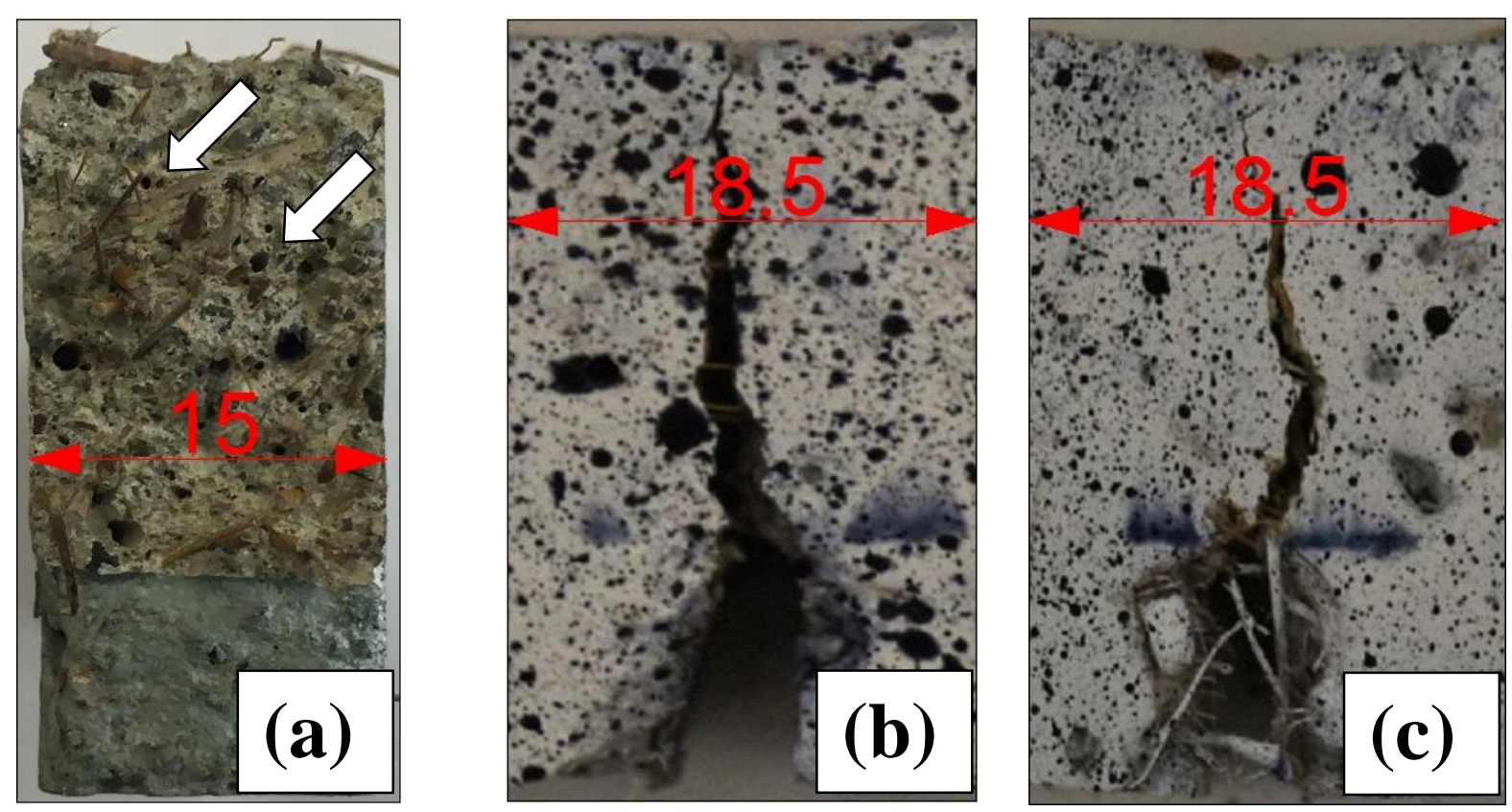

Figure 6. Toughening mechanisms: (a) debonding together with either fibre pull-out or fibre fracture; (b) debonding and bridging; (c) crack deflection (sizes in $\mathrm{mm}$ ). 


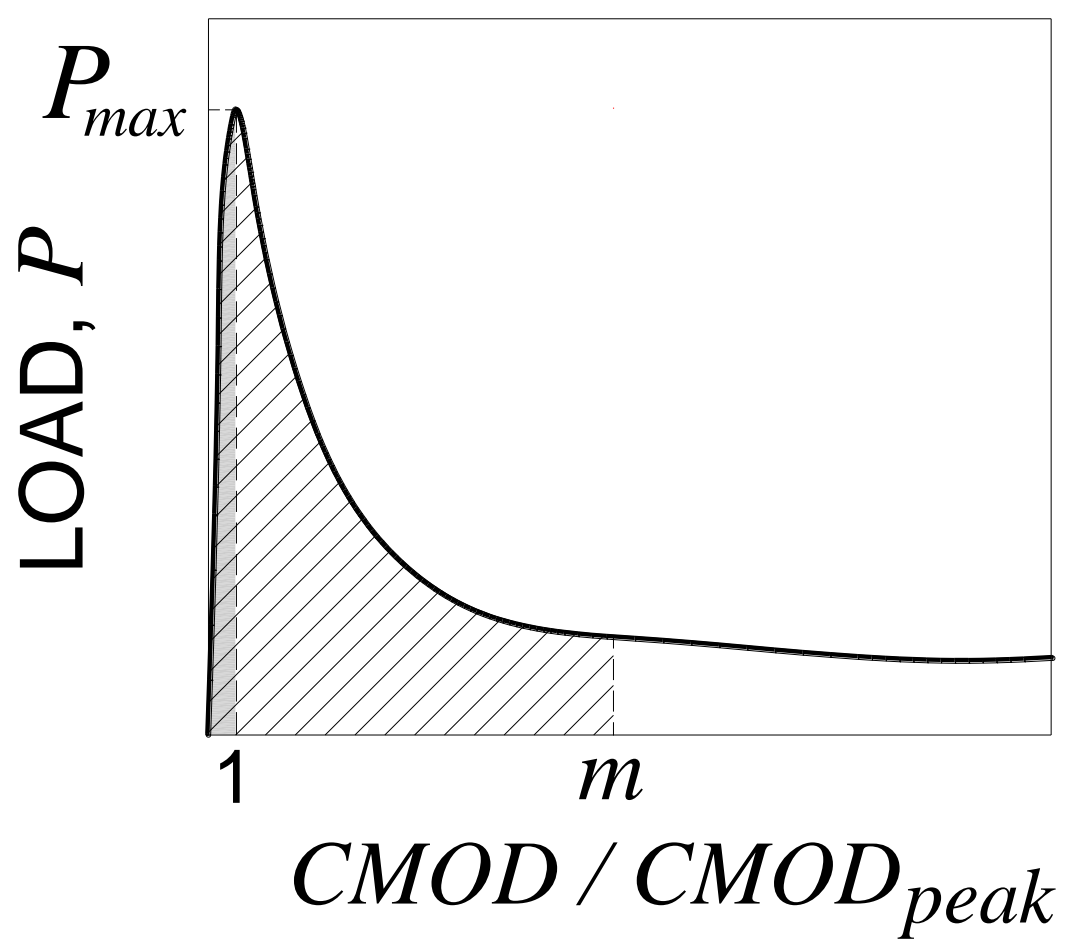

Figure 7. Definition of the toughness index $I_{t}$.

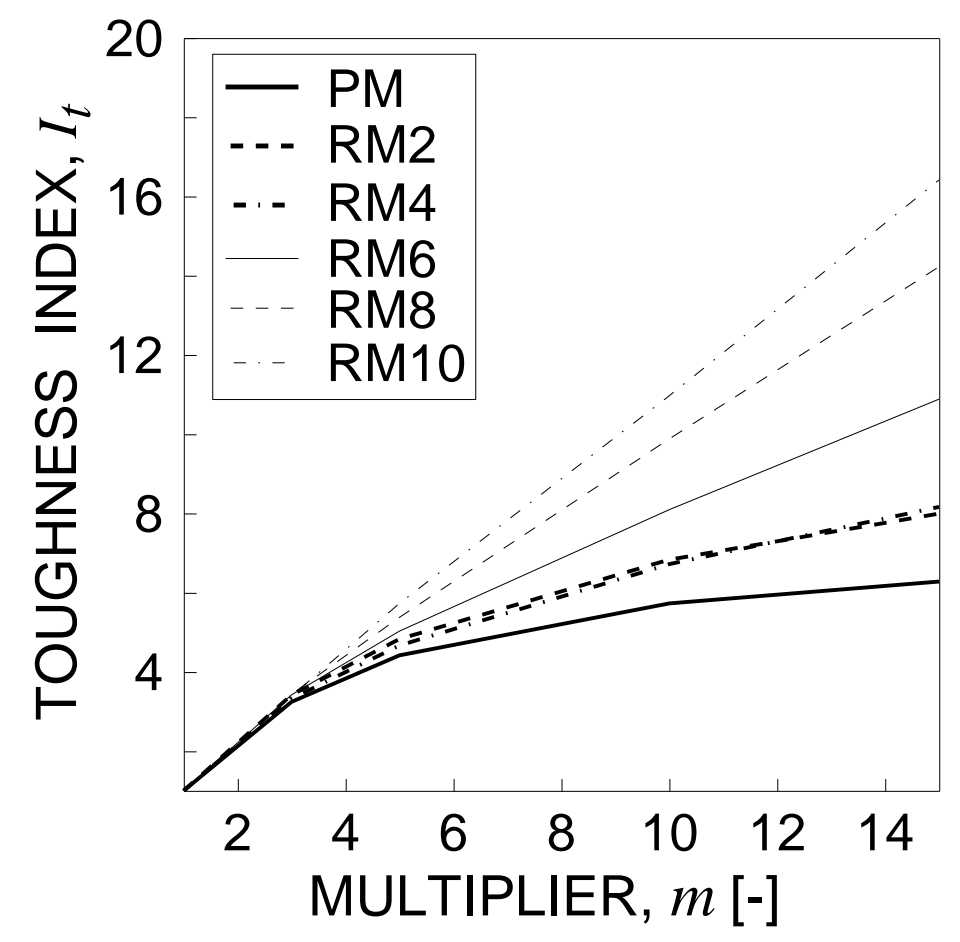

Figure 8. Toughness index $I_{t}$ as a function of the multiplier $m$, for each mortar mix examined. 


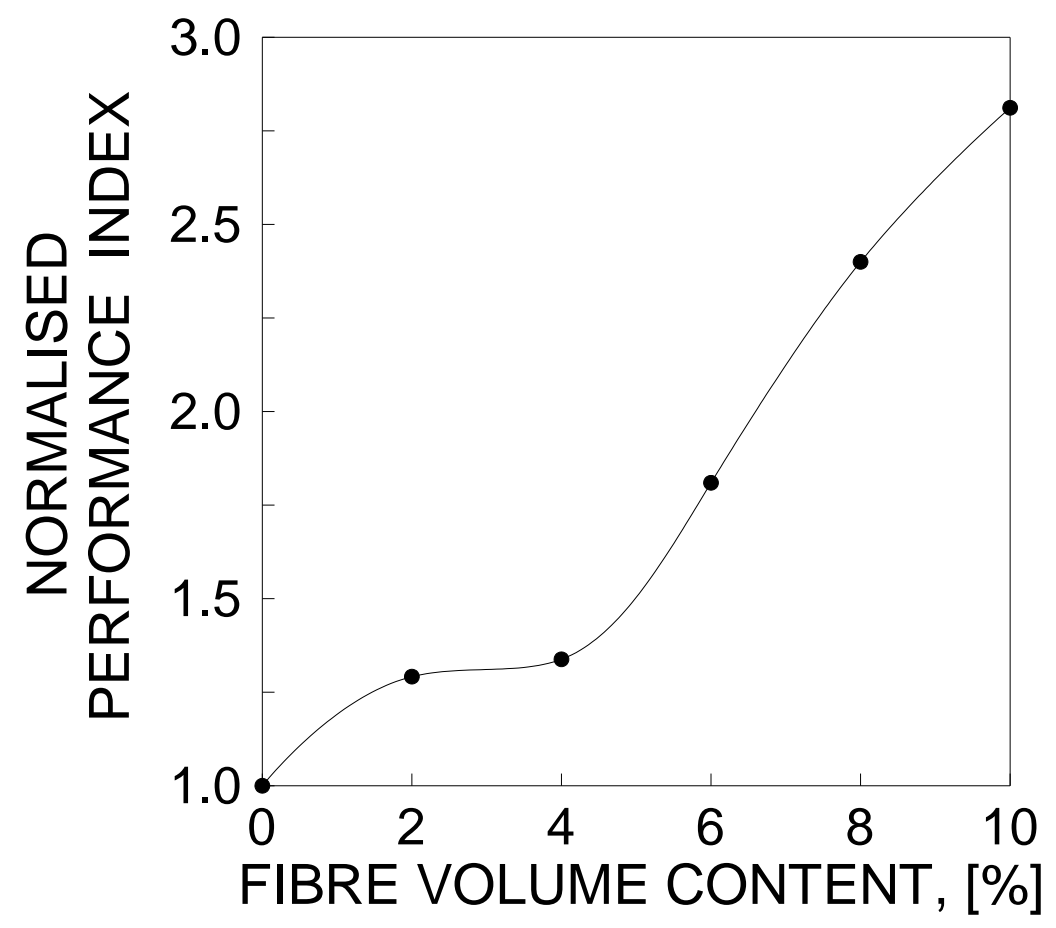

Figure 9. Normalised performance index against DPM fibre content by volume. 


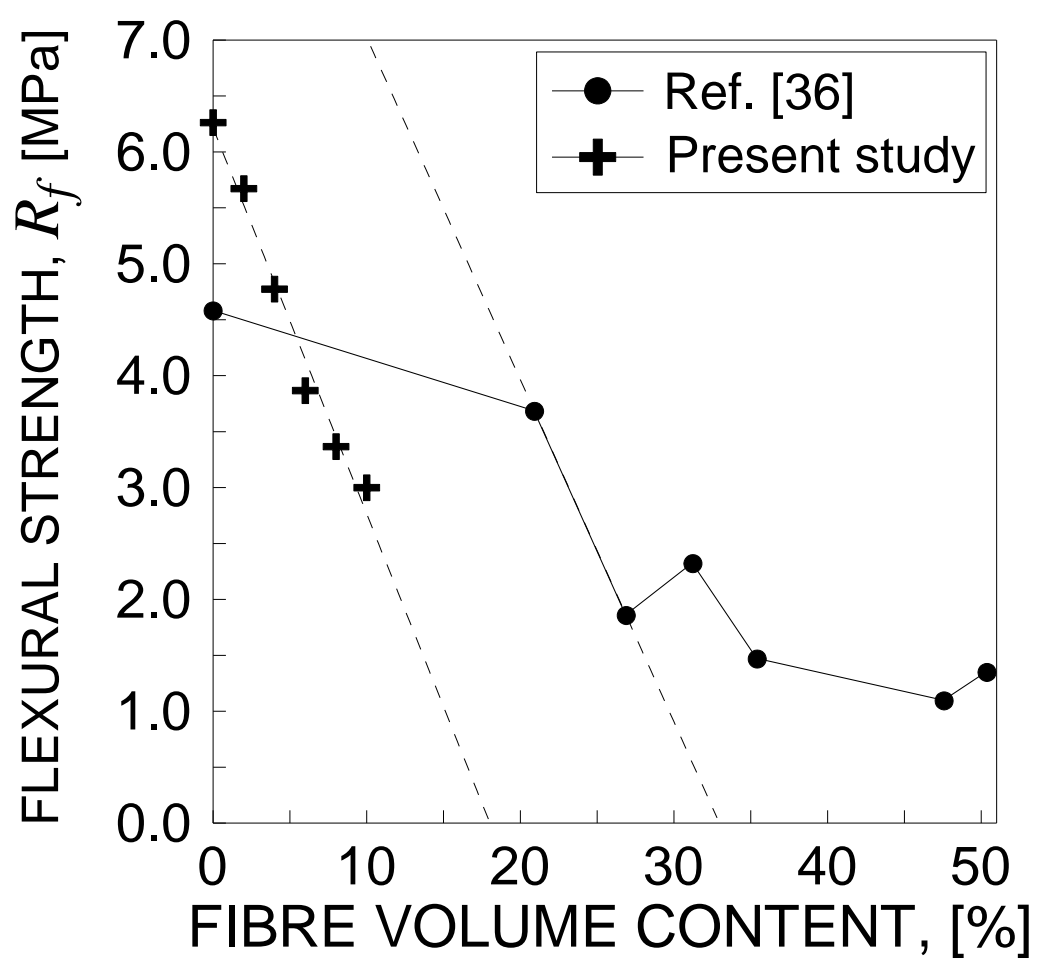

Figure 10. Flexural strength at 28 days against DPM fibre content by volume: present study results and data from the literature [36] . 